\title{
Somatic characteristics and body composition in Czech sub-elite female handball players
}

\author{
Ivana Kinkorová ${ }^{1, *}$, Eva Brožová1, Martin Komarc ${ }^{2}$
}

1 Biomedicine laboratory, Faculty of Physical Education and Sport, Charles University, Prague, Czech Republic

2 Department of Kinanthropology and Humanities, Faculty of Physical Education and Sport, Charles University, Prague, Czech Republic

* Corresponding author: kinkorova@ftvs.cuni.cz

\begin{abstract}
The somatic parameters and body composition are important indicators of physical fitness and general health not only non-athletes, but of athletes. The aim of this study was to determine the somatic characteristics and body composition in 15 (zech sub-elite female handball players (age $21.5 \pm 1.8$ years, body height $170.5 \pm 6.6 \mathrm{~cm}$, body weight $64.7 \pm 10.2 \mathrm{~kg}$, BMI $\left.22.2 \pm 2.9 \mathrm{~kg} \mathrm{~m}^{-2}\right)$. Body composition was measured by a multifrequency bioimpedance method Tanita MC-980 (Tanita Europe BV). The monitored parameters were the following: fat mass (FM), fat free mass (FFM), muscle mass (MM), bone mass (BM), total body water (TBW), intracellular water (ICW), extracellular water (ECW) and segmental analysis of muscle distribution. In our female group, we recorded the mean value of $F M=21.5 \pm 5.4 \%(14.3 \pm 5.7 \mathrm{~kg})$, FFM $=50.4 \pm 5.9 \mathrm{~kg}$, muscle mass $=47.9 \pm 5.6 \mathrm{~kg}$, bone mass $=2.6 \pm 0.3 \mathrm{~kg}, \mathrm{TBW}=56.2 \pm 3.2 \%$ $(36.2 \pm 4.8 \mathrm{~kg}), \mathrm{ICW}=22.6 \pm 3.5 \mathrm{~kg}, \mathrm{ECW}=13.6 \pm 1.3 \mathrm{~kg}$. Monitoring of muscle distribution in the extremities showed a significant difference in upper extremities $(\mathrm{p}<0.05, \mathrm{ES}<0.2)$ and in lower extremities $(p<0.05, E S<0.2)$. Our results confirm on previous data about the presence of anthropometric differences and body composition differences between individual players in handball team.
\end{abstract}

\section{KEYWORDS}

handball; body composition; fat mass; fat free mass

DOI

$10.14712 / 23366052.2020 .12$

(c) 2020 The Authors. This is an open-access article distributed under the terms of the Creative Commons Attribution License (http://creativecommons.org/licenses/by/4.0), which permits unrestricted use, distribution, and reproduction in any medium, provided the original author and source are credited. 


\section{INTRODUCTION}

Since the 1960s, handball has established itself as one of the most popular team sports (Clanton, \& Dwight, 1997). Professional and amateur handball is played in countries on every continent. World championships, continental championships, and international tournaments in handball take place regularly. Handball has been played in Olympic competition since the 1972 Games in Munich. According to the International Handball Federation, team handball is a fast-paced game involving two teams of seven players. Handball is therefore a contact sport where jumping, running, and arm throwing are prominent features of performance.

In modern elite sports based on the scientific approach to the training process, athletes have been ever more aligned according to their motor, morphological and functional characteristics, thus psychological features becoming ever more important for achievement of top results. In complex kinesiologic activities such as sport games, successful performance is determined by a number of factors, first of all by anthropologic features of the players (Rogulj, Srhoj, Nazor, Srhoj, \& Cavala, 2005). The physical and physiological characteristics are to some extent affected by the anthropometric characteristics of athletes (Čavala, Rogulj, Srhoj, Srhoj, \& Katić, 2008; Chaouachi et al., 2009; Visnapuu, \& Jürimäe, 2009). The topic of body composition in sport reguires a great deal of attention. Body composition is often viewed as central to success in sport at many levels. Although the two-compartment model of body composition (body weight $=$ fat-free mass $[\mathrm{FFM}]+$ fat mass $[\mathrm{FM}]$ ) was used in many early studies of body composition among athletes, often with a specific focus on estimates of relative FM (\%), body composition can be approached at several levels and advances in technology and methods have facilitated other assessment FFM (amount body water, muscle, bone etc.) (Malina, 2007). Body composition has been long known to be relevant to performance in sport, with special attention being paid to the total and regional proportions of fat and muscle (Leedy, Ismail, Kessler, \& Christian, 1965). Morphological characteristics of the body certainly have a great influence on an outstanding performance in handball (Šibila, \& Pori, 2009). Excessive adipose tissue acts as a dead weight in activities where the body mass must be repeatedly lifted against gravity during locomotion and jumping (Reilly, \& Doran, 1996). Studies of various authors deal with somatic characteristics and their relation to performance not only in males, but also in females (Carvalho, Mourão, \& Abade, 2014; Cichy et al., 2020; Chaouachi et al., 2009; Čavala et al., 2008; Malá, Malý, Záhalka, \& Bunc, 2010; Malá, Malý, Zahálka, Tůma, \& Bunc, Malá, 2011; Malý, Zahálka, Tůma, \& Teplan, 2012; Milanese et al., 2011; Rogulj et al., 2005; Šibila, \& Pori, 2009; Visnapuu \& Jürimäe, 2009 etc.).

The aim of this study was to determine the somatic characteristics and body composition in 15 Czech sub-elite female handball players.

\section{METHODS}

\section{Subjects}

This study contained total amount of 15 in sub-elite female handball players, in the age range of 19-25 years. The average duration of training practice for the monitored players was 6 years. This study was approved by the Ethics Committee of the Faculty 
of Physical Education and Sport, Charles University (reference number 177/2017) and measurements were performed according to the ethical standards of the Helsinki Declaration. The subjects were fully informed in advance regarding the objectives of the study, the study methods involted no risks, and written informed consent was obtained from each subject for participation in this study. All measurements were taken at the beginning of the competitive season in October. During the pre-season, sub-elite players had been training three sessions a week, $2.0 \mathrm{~h}$ per session.

\section{Body composition}

The body height $(\mathrm{cm})$ was measured by digital Stadiometer Seca 242 (Vogel \& Halke, Hamburg, Germany) to the nearest $0.1 \mathrm{~cm}$. The body weight was measured on a digital Scale to the nearest $0.1 \mathrm{~kg}$. The body mass index (BMI, in $\mathrm{kg} \mathrm{m}^{-2}$ ) was calculated. Body composition was measured by a multifrequency bioimpedance method Tanita MC-980 (Tanita Europe BV), which operates on frequencies (1, 5, 50, 250, 500, $1000 \mathrm{kHz}$ ). BIA analysing time was about $40 \mathrm{~s}$. The monitored parameters were the following: fat mass (FM), fat free mass (FFM), muscle mass (MM), bone mass (BM), total body water (TBW), intracellular water (ICW), extracellular water (ECW) and segmental analysis of muscle distribution.

\section{Data Analysis}

Basic descriptive statistics (mean, standard deviation) were computed for all variables, which were subsequently tested for normality using Shapiro-Wilk tests. Differences in segmental analysis from BIA were evaluated by Student's t-test (significance was accepted at $\mathrm{p}<0.05)$ and an index of effect size - ES (Cohen's d). The effect size (ES) was assessed as follows: $\mathrm{ES}<0.20$ (small effect), $\mathrm{ES}=0.50$ (medium effect), $\mathrm{ES}>0.80$ (large effect). Statistical analyses were performed using Microsoft Excel (2010), SPSS version 22 (SPSS Inc., Chicago, IL, USA).

\section{RESULTS}

Total amount of 15 sub-elite female handball players (average age $-21.5 \pm 1.8$ years). Values of basic somatic characteristics of probands (body weight, body height, BMI) are shown in Table 1. Values of parameters indicating body composition - BIA Tanita MC-980 are show in Table 2. All data were normally distributed.

Table 1 Values of basic somatic characteristics of probands $(n=15)$

\begin{tabular}{l|c|c}
\hline & mean (SD) & $(\min -\max )$ \\
\hline Age (years) & $21.5(1.8)$ & $(19.0-25.0)$ \\
\hline Body weight $(\mathrm{kg})$ & $64.7(10.2)$ & $(46.8-87.5)$ \\
\hline Body height $(\mathrm{cm})$ & $170.5(6.6)$ & $(155.8-185.7)$ \\
\hline BMl $\left(\mathrm{kg} \mathrm{m}^{-2}\right)$ & $22.2(2.9)$ & $(18.5-28.7)$ \\
\hline
\end{tabular}

Note: Data are reported as means \pm SD.

SD - standard deviation; BMI - Body mass index. 
Table 2 Values of parameters from body composition - BIA Tanita MC-980 $(n=15)$

\begin{tabular}{l|r|r}
\hline & mean (SD) & (min-max) \\
\hline FM (\%) & $21.5(5.4)$ & $(14.5-31.5)$ \\
FM (kg) & $14.3(5.7)$ & $(8.4-27.6)$ \\
\hline FFM (kg) & $50.4(5.9)$ & $(38.4-59.9)$ \\
Muscle mass (kg) & $47.9(5.6)$ & $(36.2-56.9)$ \\
Bone mass (kg) & $2.6(0.3)$ & $(2.0-3.0)$ \\
\hline TBW (\%) & $56.2(3.2)$ & $(50.4-61.6)$ \\
\hline TBW (kg) & $36.2(4.8)$ & $(26.7-45.2)$ \\
ICW (kg) & $22.6(3.5)$ & $(15.8-28.8)$ \\
ECW (kg) & $13.6(1.3)$ & $(10.9-16.3)$ \\
Left arm (kg) & $2.45(0.5)$ & $(1.5-3.6)$ \\
Right arm (kg) & $2.50(0.4)^{*}$ & $(1.6-3.3)$ \\
Trunk (kg) & $26.8(4.9)$ & $(6.0-30.2)$ \\
Left leg (kg) & $8.12(1.0)^{*}$ & $(6.2-9.7)$ \\
Right leg (kg) & $8.01(0.9)$ & \\
\hline
\end{tabular}

Note: Data are reported as means \pm SD.

SD - standard deviation; FM - fat mass; FFM - fat free mass; TBW - total body water; ICW - intracellular water; ECW - extracellular water; ${ }^{*}$ - significant difference between left/right extremities at $p<0.05$.

When comparing paired extremities of handball players we found significant differences in muscle mass proportion (difference between right arm and left arm $0.05 \mathrm{~kg}, \mathrm{p}<0.05, \mathrm{ES}<0.2$; difference between right leg and left leg $-0.11 \mathrm{~kg}, \mathrm{p}<0.05$, $\mathrm{ES}<0.2)$.

\section{DISCUSSION AND CONCLUSION}

In general, to succeed in a sport, it is important usually to have specific bodily attributes (Malina, Bouchard, \& Bar-Or, 2004). Handball players occupying different positions differ in many morphological parameters (Šibila, \& Pori 2009). Only limited information is available on anthropometric differences between handball players characterised by their playing position (e.g. Rogulj et al., 2005; Šibila, \& Pori, 2009).

In our group of female handball players, we measured these results of somatic characteristics (body height $170.5 \pm 6.6 \mathrm{~cm}$, body weight $64.7 \pm 10.2 \mathrm{~kg}$, BMI $22.2 \pm$ $\left.2.9 \mathrm{~kg} \mathrm{~m}^{-2}\right)$ and body composition $(\mathrm{FM}=21.5 \pm 5.4 \%(14.3 \pm 5.7 \mathrm{~kg}), \mathrm{FFM}=50.4 \pm$ $5.9 \mathrm{~kg}$, muscle mass $=47.9 \pm 5.6 \mathrm{~kg}$, bone mass $=2.6 \pm 0.3 \mathrm{~kg}, \mathrm{TBW}=56.2 \pm 3.2 \%$ $(36.2 \pm 4.8 \mathrm{~kg}), \mathrm{ICW}=22.6 \pm 3.5 \mathrm{~kg}, \mathrm{ECW}=13.6 \pm 1.3 \mathrm{~kg})$. We found relatively large interindividual differences in the monitored somatic parameters (body height difference $29.9 \mathrm{~cm}$, body weight - difference $40.7 \mathrm{~kg}$, BMI - difference $10.2 \mathrm{~kg} \mathrm{~m}^{-2}$, FM - difference 17\%, FFM - difference $21.7 \mathrm{~kg}$, muscle mass - difference $20.7 \mathrm{~kg}$, TBW - difference $11.2 \%$ ). Monitoring of muscle distribution in the extremities showed a significant difference in upper extremities (difference between right arm and left arm $-0.05 \mathrm{~kg}, \mathrm{p}<0.05$, ES $<0.2$ ) and in lower extremities (difference between right leg and left leg $-0.11 \mathrm{~kg}, \mathrm{p}<0.05$, ES $<0.2$ ). Our results of segmental muscle distribution support the claim of Malá et al. (2012), that fluid distribution in the body 
may indicate possible muscle imbalance as a result of unilateral physical exercise. The different segmental muscle mass proportion between preferred and non-preferred hand (leg) may represent a potential risk of a player's injury; therefore the detected asymmetries should be systematically monitored and compensated using specific exercises (Malá et al., 2012).

Comparison of the percent body fat values found in our sample with those in the literature is difficult, because the skinfold equations used by others tend to underestimate percent fat mass in comparison with BIA. Hasan et al. (2007) showed the mean somatic parameters of elite Asian female handball players (height $170.0 \pm 6.8 \mathrm{~cm}$, weight $64.6 \pm 7.7 \mathrm{~kg}, \mathrm{FM}_{\text {skinfold thickness }}=20.8 \pm 4.4 \%$ ). C Cavala et al. (2008) found the mean somatic parameters of Croatian elite female handball players (height $178.2 \pm$ $3.6 \mathrm{~cm}$, weight $73.5 \pm 7.1 \mathrm{~kg}$ ). Milanese et al. (2011) showed the mean somatic parameters of handball players from the Italian championships (elite players - height $169.2 \pm 6.1 \mathrm{~cm}$, weight $67.0 \pm 7.9 \mathrm{~kg}$, BMI $23.4 \pm 5.3 \mathrm{~kg} \mathrm{~m}^{-2}, \mathrm{FM}_{\mathrm{DXA}}=23.3 \pm 5.3 \%$; subelite players - height $166.0 \pm 5.1 \mathrm{~cm}$, weight $64.4 \pm 10.5 \mathrm{~kg}$, BMI $23.3 \pm 4.0 \mathrm{~kg} \mathrm{~m}^{-2}$, $\left.\mathrm{FM}_{\mathrm{DXA}}=28.6 \pm 4.0 \%\right)$. The elite female players were higher, heavier and had a lower fat mass (\%) than the amateur players. The authors concluded that a high body mass and specifically high fat-free mass is advantageous in handball. In contrast, a study of first division and second division Greek handball players showed no differences between divisions in terms of height or body mass (Bayios, Anastasopoulou, Sioudris, \& Boudolos, 2001). Malá et al. (2011) found body composition of a national team of female handball players (height $176.0 \pm 6.5 \mathrm{~cm}$, weight $72.5 \pm 8.3 \mathrm{~kg}, \mathrm{FM}_{\mathrm{BIA}}=16.06 \pm$ $0.65 \%, \mathrm{FFM}_{\text {BIA }}=60.74 \pm 1.48 \mathrm{~kg}, \mathrm{TBW}_{\text {BIA }} 54.98 \%$, ICW $67.88 \%$, ECW $\left.42.12 \%\right)$. In next study of Malá et al. (2012) were these results of body composition in female handball players (height $175.9 \pm 6.5 \mathrm{~cm}$, weight $72.5 \pm 8.3 \mathrm{~kg}, \mathrm{BMI}=23.4 \pm 2.3 \mathrm{~kg} \mathrm{~m}^{-2}$, $\mathrm{FM}_{\mathrm{BIA}}=20.2 \pm 4.1 \%, \mathrm{FFM}_{\mathrm{BIA}}=57.8 \pm 5.3 \mathrm{~kg}, \mathrm{TBW}_{\mathrm{BIA}}=42.6 \pm 3.9$ l, i.e. $\left.58.7 \%\right)$. Cichy et al. (2020) found the mean somatic parameters of Polish female handball players (height $176.3 \mathrm{~cm}$, weight $70.6 \mathrm{~kg}, \mathrm{BMI}-22.8 \mathrm{~kg} \mathrm{~m}^{-2}, \mathrm{FM}_{\mathrm{BIA}}-19.1 \%, \mathrm{FFM}_{\mathrm{BIA}}-$ $\left.56.9 \mathrm{~kg}, \mathrm{TBW}_{\text {BIA }}-59.1 \%\right)$.

There is a need for detailed anthropometric and body composition studies of handball players.

The measurement of physical (anthropometry, somatotypes, body composition) and physiological characteristics gives a great insight into the current status of handball players and allows coaches to evaluate such players (selection) and implicate the right training volume and intensity to raise their capabilities (preparation cycles programming) (Malá et al., 2011). And especially, the results could be useful in profiling players and identifying talents and/or could direct coaches' attention to improve specific body composition characteristics of athletes. Although body composition analysis are useful for providing reasonable guidelines for the percentage of body fat in this sport, caution must be exercised when interpreting such data due to the methods of assessing body fat (skinfold thickness measurement vs. DXA vs. BIA etc.).

\section{ACKNOWLEDGEMENTS}

This study was supported by the project PROGRES Q41. 


\section{REFERENCES}

Bayios, I. A., Anastasopoulou, E. M., Sioudris, D. S., \& Boudolos, K. D. (2001). Relationship between isokinetic strength of the internal and external shoulder rotators and ball velocity in team handball. Journal of Sports Medicine and Physical Fitness, 41(2), 229-235.

Carvalho, A., Mourão, P., \& Abade, E. (2014). Effects of strength training combined with specific plyometric exercises on body composition, vertical jump height and lower limb strength development in elite male handball players: a case study. Journal of Human Kinetics, 41(1), 125-132.

Cichy, I., Dudkowski, A., Kociuba, M., Ignasiak, Z., Sebastjan, A., Kochan, K., ..., \& Malina, R. M. (2020). Sex Differences in Body Composition Changes after Preseason Training in Elite Handball Players. International Journal of Environmental Research and Public Health, 17(11), 3880.

Chaouachi, A., Brughelli, M., Levin, G., Boudhina, N. B., Cronin, J., \& Chamari, K. (2009). Anthropometric, physiological and performance characteristics of elite team-handball players. Journal of Sports Sciences, 27(2), 151-157.

Čavala, M., Rogulj, N., Srhoj, V., Srhoj, L., \& Katić, R. (2008). Biomotor structures in elite female handball players according to performance. Collegium antropologicum, 32(1), 231-239.

Clanton, R. E., \& Dwight, M. P. (1997). Team handball: Steps to success. Champaign, IL: Human Kinetics.

Hasan, A. A., Reilly, T., Cable, N. T., \& Ramadan, J. (2007). Anthropometric profile of elite Asian female handball players. The Journal of Sports Medicine and Physical Fitness, 47(2), 197-202.

Leedy, H. E., Ismail, A. H., Kessler, W. V., \& Christian, J. E. (1965). Relationships between physical performance and body composition. Research Quarterly, 36(2), 158-163.

Malá, L., Malý, T., Záhalka, F., \& Bunc, V. (2010). The profile and comparison of body composition of elite female volleyball players. Kinesiology, 42(1), 90-97.

Malá, L., Malý, T., Zahálka, F., Tůma, M., \& Bunc, V. (2011). Body composition of elite handball players. Acta Universitatis Carolinae Kinanthropologica, 47(1), 119-128.

Malá, L., Malý, T., Zahálka, F., Tůma, M., \& Teplan, J. (2012). Telesné zloženie a distribúcia tekutín u vrcholových hádzanárok Body composition and distribution of liquids in female elite handball players. Studia Sportiva, 6(1), 99-106.

Malina, R. M., Bouchard, C., \& Bar-Or, O. (2004). Growth, maturation, and physical activity (2nd ed.). Champaign, IL: Human Kinetics.

Malina, R. M. (2007). Body composition in athletes: assessment and estimated fatness. Clinics in sports medicine, 26(1), 37-68.

Milanese, C., Piscitelli, F., Lampis, C., \& Zancanaro, C. (2011). Anthropometry and body composition of female handball players according to competitive level or the playing position. Journal of Sports Sciences, 29(12), 1301-1309.

Reilly, T., \& Doran, D. (1996). Fitness assessment. In: T. Reilly (Ed.), Science and soccer (pp. 25-50). London: E \& FN Spon.

Rogulj, N., Srhoj, V., Nazor, M., Srhoj, L., \& Čavala, M. (2005). Some anthropologic characteristics of elite female handball players at different playing positions. Collegium Antropologicum, 29(2), 705-709.

Šibila, M., \& Pori, P. (2009). Position-related differences in selected morphological body characteristics of top-level handball players. Collegium Antropologicum, 33(4), 1079-1086.

Visnapuu, M., \& Jürimäe, T. (2009). Relations of anthropometric parameters with scores on basic and specific motor tasks in young handball players. Perceptual and motor skills, $108(3), 670-676$. 